\title{
NEIGHBORHOOD COMPETITION IN AN OLD-FIELD PLANT COMMUNITY ${ }^{1}$
}

\author{
DEBORAH E. GOLDBERG \\ Department of Biology, University of Michigan, Ann Arbor, Michigan 48109 USA
}

\begin{abstract}
A series of field neighborhood experiments was performed to compare the competitive effects of seven plant species on the performance of transplanted individuals of Solidago canadensis. The neighbor species included conspecifics and species of a variety of growth forms that co-occur with $S$. canadensis in old fields. There were strong competitive effects on the transplants; average $S$. canadensis growth was reduced $17-62 \%$ by the presence of neighbors growing at natural densities. The responses to gradients of increasing neighbor density or biomass appeared to be nonlinear, with decreasing effects of adding more neighbors at higher neighbor density or biomass.

Competitive effects were compared among neighbor species at three levels: effects at natural densities, per-individual (population density) effects, and per-gram (biomass density) effects. The magnitude of total effects at natural densities varied with the species of neighbor plants and was stronger for neighbor species with greater total biomass of plants per unit area. The magnitude of effects of each individual also varied with neighbor species and was stronger for neighbor species with larger mean biomass per individual. Consequently, per-gram competitive effects did not differ among the neighbor species. Thus, it appears that the differences in competitive effects among species were primarily due to differences in size or abundance, rather than to more subtle differences in aspects of resource use.

The responses of target Solidago canadensis individuals to neighborhood competition were very variable. A maximum of $40 \%$ of the variance in individual performance was explained by any one of the measures of abundance of neighbors, and, in half of the neighbor species, $<10 \%$ of the variance in target performance was explained by abundance of neighbors. Competition intensity seems to limit the maximum potential growth of individuals, but actual growth was often below the boundary determined by competition.
\end{abstract}

Key words: competition; interference; neighborhood effects; old fields; Solidago canadensis.

\section{INTRODUCTION}

There is abundant evidence that competition for resources can have strong effects on survival, growth, and reproduction of individual plants (see reviews by Harper 1977, Connell 1983, Schoener 1983). However, extension of these effects on individuals into effects of interspecific competition on the relative abundance of species within communities also requires an understanding of how and why species differ in their competitive abilities. As an extreme case, if all species in a community have completely equal competitive abilities for shared, limiting resources, there may be no effect of competition on relative abundances, even though there may be strong effects of removal of competitors on components of fitness of the remaining plants. Despite the importance of comparisons of competitive ability among species for our understanding of the impact of interspecific competition on community structure, there have been surprisingly few field experiments where the magnitude of competitive effects has been explicitly compared among species on

\footnotetext{
1 Manuscript received 7 October 1985; revised 1 December 1986; accepted 6 December 1986.
}

some standardized basis such as per-individual or perunit-size (Connell 1983).

Both per-individual and per-unit-size competitive effects are often expected to be stronger for conspecifics or more closely related species because of greater overlap in resource requirements. However, because all autotrophic plants require the same, few resources, the extent of differentiation in resource use among plant species may be relatively limited and it has been suggested that competitive effects often may be more or less equivalent among co-occurring species (Aarssen 1983, Goldberg and Werner 1983, Agren and Fagerstrom 1984, Shmida and Ellner 1984, Hubbell and Foster 1986). Because average plant size varies greatly among species or among sites for a given species, this hypothesis predicts that competitive effects will be equivalent among co-occurring species on a per-unitsize basis, but not necessarily on a per-individual basis.

In this paper, I compare the per-individual and perunit-size competitive effects of seven plant species on one "target" species. The competitor species include conspecifics of the target species, congeners of the target species, and more distantly related species with a variety of growth forms. To measure per-individual and per-unit-size competitive effects, I used a neighbor- 
hood experimental design, where performance (e.g., growth, reproduction) of single individuals of the target species is related to total abundance (e.g., density, biomass) and spatial arrangement of neighboring plants (Mack and Harper 1977). When only a single species of neighbor is present, the slope of the regression of target plant performance on neighbor density or biomass is a measure of the effect of a single individual or a single unit of mass of that neighbor species (Goldberg and Werner 1983, Pacala and Silander 1985, Silander and Pacala 1985). The slopes are referred to as per-individual or per-gram competitive effects.

The regressions also give the proportion of variance in target plant performance that can be accounted for by variation in the abundance of neighbors and thus provide an indication of the importance of competition relative to other factors affecting performance. This has been the primary use of neighborhood experiments to date (Mack and Harper 1977, Waller 1981, Liddle et al. 1982, Weiner 1982, 1984, Fowler 1984, Mithen et al. 1984).

\section{Methods}

Species descriptions. - The target species used was Solidago canadensis var. scabra (Muhl.) T. and G. (Asteraceae), a cloning herbaceous perennial, dominant in midsuccessional old fields throughout much of the northeastern and midwestern United States (see Werner et al. 1980 for discussion of taxonomy and general ecology). The neighbor species were all herbaceous perennials that are common associates of $S$. canadensis and were chosen to represent various degrees of taxonomic relatedness and a variety of growth forms. The neighbors included three species of tall leafy dicots, all in the same family as the target plant: Solidago canadensis var. scabra (intraspecific competition), S. graminifolia (intrageneric competition), and Aster pilosus. There were also two species that form rosettes, Daucus carota (Apiaceae) and Achillea millefolium (Asteraceae), and two grasses, Agropyron repens and Bromus inermis. All species except Aster pilosus and Daucus carota are rhizomatous, and all except Daucus carota, which has a tap root, have spreading root systems concentrated near the soil surface (mostly in the top 10 $15 \mathrm{~cm}$ : D. Goldberg, personal observation). Together, these species compose up to $75 \%$ of the biomass of typical old fields in southwestern Michigan.

Each of the seven neighbor species was used in a separate experimental treatment with target plants surrounded by a single neighbor species. There were also two mixtures of species: all three tall, leafy dicot species in the same plots and both rosette dicot species in the same plots.

Experimental site. - The experiments were performed in three abandoned agricultural fields at the $W$. K. Kellogg Biological Station in southwestern Michigan, USA. Upper McKay Field was abandoned from agriculture in 1976, and the vegetation was a mixture of herbaceous dicots, especially Solidago canadensis and Aster pilosus. Lower McKay Field $(\approx 100 \mathrm{~m}$ from upper McKay Field) was abandoned from agriculture in 1973 and was an almost pure stand of Agropyron repens. Bailey Field $(\approx 1 \mathrm{~km}$ from McKay Field), was abandoned from agriculture in 1972 and was an almost pure stand of Bromus inermis.

In September 1981, transects at least $2 \mathrm{~m}$ apart and ranging from 10 to $50 \mathrm{~m}$ long were laid out in the three fields. Along each transect, a $50 \mathrm{~cm}$ diameter plot was established at every location with at least $75 \%$ cover of one of the designated neighbor species with the constraint that edges of adjacent plots were at least $1 \mathrm{~m}$ apart. There were 50 plots for each neighbor species, except $S$. graminifolia ( 25 plots), for a total of 425 plots. The plots for all of the dicot neighbor species, including the two mixtures, were well mixed in upper McKay Field. However, the two grass neighbor species were relatively infrequent in this field, and so the plots for these species were established in pure stands of these grasses in lower McKay (Agropyron repens) or Bailey Fields (Bromus inermis).

Target planting. - A single ramet of Solidago canadensis was transplanted into the center of each of the plots in September 1981. The ramets were taken from 25 Solidago canadensis clones growing in a field 0.5 $\mathrm{km}$ north of McKay Field. The set of 50 plots for each neighbor species included two ramets from each of the 25 clones (one ramet per clone for the $25 \mathrm{~S}$. graminifolia neighbor plots). A tulip bulber was used to take an $8 \mathrm{~cm}$ diameter core of soil $10-12 \mathrm{~cm}$ deep from around the base of each of 17 flowering stems at the periphery of each clone. Each core included the current season's rhizome and several rhizome buds that gave rise to the next season's stems. The transplants were stored in plastic bags and replanted within $48 \mathrm{~h}$. Transplants were placed into a hole about $15 \mathrm{~cm}$ wide and $20 \mathrm{~cm}$ deep in the center of each plot and the soil around each core was replaced.

Density gradients. - In April-May 1982 the density gradients were established. All plants not of the designated neighbor species were removed in all plots. (Removals were done by clipping plants at ground level in order not to disturb the soil.) Nine of the plots for each species were randomly chosen to be "completeremovals" (all plants of the neighbor species removed), and nine of the plots were chosen to be "no-removals" (no plants of the neighbor species removed). The remaining 32 plots were randomly assigned to densities between zero and the mean density of the neighbor species in the no-removal plots. In each plot, individuals of the neighbor species were removed until the assigned density was reached. Some of the 32 plots chosen to be "partial-removals" already had densities equal to or less than the assigned density. These plots were grouped with the no-removal plots in the analyses.

The density gradients were maintained by clipping 
TABle 1. Emergence and survival of Solidago canadensis target transplants. Values with the same letter within columns are not significantly different $(P>.05)$ by an STP $G$ test (Sokal and Rohlf 1981: 728-731).

\begin{tabular}{lccc}
\hline \hline & $\begin{array}{c}\text { Num- } \\
\text { ber of } \\
\text { trans- } \\
\text { plants } \dagger\end{array}$ & $\begin{array}{c}\text { Proportion } \\
\text { emerged }\end{array}$ & $\begin{array}{c}\text { Proportion } \\
\text { of emerged } \\
\text { that survived } \\
\text { to harvest }\end{array}$ \\
\hline Neighbor species & & & \\
Tall dicots & 49 & $0.86^{\mathrm{a}}$ & $0.83^{\mathrm{a}}$ \\
$\quad \begin{array}{l}\text { Solidago canadensis } \\
\text { S. graminifolia }\end{array}$ & 24 & $0.96^{\mathrm{a}}$ & $0.96^{\mathrm{ab}}$ \\
Aster pilosus & 48 & $0.90^{\mathrm{a}}$ & $1.00^{\mathrm{b}}$ \\
Mixed tall dicots & 50 & $0.76^{\mathrm{ab}}$ & $1.00^{\mathrm{b}}$ \\
Rosette dicots & & & \\
Daucus carota & 50 & $0.90^{\mathrm{a}}$ & $0.98^{\mathrm{b}}$ \\
Achillea millefolium & 50 & $0.92^{\mathrm{a}}$ & $0.98^{\mathrm{b}}$ \\
Mixed rosette dicots & 49 & $0.86^{\mathrm{a}}$ & $0.98^{\mathrm{b}}$ \\
Grasses & & & \\
Agropyron repens & 50 & $0.88^{\mathrm{a}}$ & $0.91^{\mathrm{ab}}$ \\
Bromus inermis & 50 & $0.48^{\mathrm{b}}$ & $0.79^{\mathrm{a}}$ \\
Total & 420 & 0.83 & 0.94 \\
G & & $45.78^{* * *}$ & $26.84^{* * *}$ \\
df & & 8 & 8 \\
\hline
\end{tabular}

$\uparrow$ The number of transplants (plots) is less than the original 50 (or 25 for $S$. graminifolia) because of damage to plots by animal activity.

$\ddagger G$ values are for differences in transplant emergence or survival among neighbor species (Sokal and Rohlf 1981: 744746).

*** $P<.001$.

twice during the growing season. As a result of this repeated clipping, the density gradients were also biomass gradients, i.e., neighbor density was significantly positively correlated with neighbor biomass for all neighbor species. In mid-July, the vegetation immediately adjacent to each plot was cut down to a height of $25 \mathrm{~cm}$ so that plants outside the plots did not shade the target plants.

Harvest. - In September 1982, above- and belowground biomass of targets and neighbors were harvested from each plot. The neighbors were harvested separately from three annuli around the target plant: $0-7.5 \mathrm{~cm}, 7.5-15 \mathrm{~cm}$, and $15-22.5 \mathrm{~cm}$ from the target. Plots $45 \mathrm{~cm}$ in diameter rather than the original $50 \mathrm{~cm}$ diameter plots were harvested because the target ramets did not always emerge in the exact center of the plots, and it was desired to center the annuli to be harvested around the target ramets and still stay within the plot boundaries. All roots down to $\approx 10 \mathrm{~cm}$ depth that were attached to plants within each annulus were collected. Undoubtedly, many of the fine roots of all plants were lost during the harvesting procedure. However, the values obtained still should indicate relative amounts of total root material in each plot. Any plants that were not of the designated neighbor species that had regrown since the last clipping were also harvested from each annulus. "Unattached roots" from within each annulus were collected separately. These were either from plants with stems emerging from the ground outside the plot or from plants clipped from the plots and surviving only as roots and/or rhizomes. A soil sample was collected from the loosened soil in the center of each plot after the target plant had been removed.

All target and neighbor plants were divided into roots, rhizomes, stems, leaves, and inflorescences, dried at $65^{\circ} \mathrm{C}$ for $48 \mathrm{~h}$, and weighed. Height of all targets and height and number of neighbor stems in the plots with only one species of neighbor were also recorded. Soil samples were analyzed for texture using the hydrometer method (Day 1965).

Analysis. - Transplant success (number of transplants emerging out of number planted), transplant survival (number of transplants at final harvest out of number emerged), and frequency of flowering of transplants were compared between the extremes of the density gradient (no-removals vs. complete-removals) and among neighbor species, with $G$ tests (Sokal and Rohlf 1981).

Effects of competition on target plant biomass at the final harvest were analyzed in two ways. First, effects of the presence of neighbors at their natural density and of the species identity of neighbors were determined with a two-way ANOVA, using only the noremoval and the complete-removal plots for each neighbor species. In the second analysis, target plant performance was assessed over the entire gradient of density or biomass of each neighbor species using linear and nonlinear regressions. The nonlinear regressions were fit with a pseudo-Gauss-Newton iterative algorithm using the BMDP program PAR (Dixon 1983), and $R^{2}$ were calculated as 1 - (residual SS/total SS). Competitive effects were compared among neighbor species using analysis of covariance, using the slopes from the linear regressions only. There is no straightforward way to apply significance tests to the nonlinear regressions.

\section{RESULTS \\ Survival and flowering}

Five of the original 425 transplants were eliminated from the experiment because of disturbance to plots by burrowing mammals or accidental damage during transplanting or censusing. Of the remaining transplants, $83 \%$ emerged from rhizomes the spring following transplanting. Transplant success was similar among neighbor species (76-92\%), except for an exceptionally low emergence of transplants with Bromus inermis neighbors (48\%; Table 1). Because almost all transplants emerged from the soil during May while the density gradients were being established, it is unlikely that there were any effects of the manipulations of density on transplant success, so only plots with emerged transplants were harvested. The cause of the poor transplant success with Bromus inermis neighbors is unknown, although one possibility is a negative effect of the very deep litter layer found in the Bromus plots. 
Survival of transplants that did emerge was high overall (94\%), but was significantly different among neighbor species (Table 1). Transplants with Solidago canadensis or Bromus inermis neighbors had lower survival ( 83 and $79 \%$, respectively) than did transplants with any of the other neighbor species (91-100\%; Table 1). The mortality with Bromus inermis neighbors was mostly due to breakage of stems of the transplants when Bromus stems lodged during heavy rains. The source of mortality with Solidago canadensis neighbors is unknown.

Mortality was not significantly different between the no-removal and complete-removal plots when all neighbor species were grouped together (95 vs. $96 \%$, respectively, $G=0.032$, df $=1, P>.50$ ). It was not possible to compare mortality between these treatments within each neighbor species because expected values were too low. Only target transplants that survived to the end of the growing season are considered in all subsequent analyses. Even if the few, dead transplants were included in the analyses as having a final biomass of zero the results did not change.

Only 35 target plants of 327 surviving to the end of the experiment flowered, so there were insufficient data to analyze fecundity as a function of density or biomass of neighbors. Twice as many transplants flowered in the complete-removal plots as in the no-removal plots (14 vs. $7 \%$ ), although the difference was not significant $(G=2.52$, df $=1, P>.10)$. Because fecundity and survival in plants is often strongly positively correlated with total plant biomass, I used total target plant biomass (root + shoot) as an index of target plant performance for most subsequent analyses.

\section{Effects of presence of neighbors on growth of target plants}

Target plant biomass was significantly less in the noremoval plots than in the complete-removal plots $(F=$ $15.80 ; \mathrm{df}=1,137 ; P<.001)$ and differed significantly among neighbor species $(F=3.05 ; \mathrm{df}=8,137 ; P<$ $.01)$. However, the interaction between the removal treatments and species of neighbor was not significant in the two-way ANOVA $(F=0.24 ; \mathrm{df}=8,137 ; P>$ $.10)$. The magnitude of the competitive effect of each neighbor species was related to its abundance: neighbor species with greater mean biomass in the no-removal plots caused a larger percent reduction in target plant biomass (Fig. $1 ; r_{s}=0.83 ; \mathrm{df}=7 ; P<.01$ ).

\section{Descriptions of target-neighbor relationships}

Negative relationships between biomass of individual target plants and neighbor density (Fig. 2) or neighbor biomass (Fig. 3) are apparent for each neighbor species, although the relationships were much more variable than that of the among-species comparisons (Fig. 1). To describe these relationships, I used regressions of target plant biomass on neighbor biomass to determine the most appropriate mathematical function

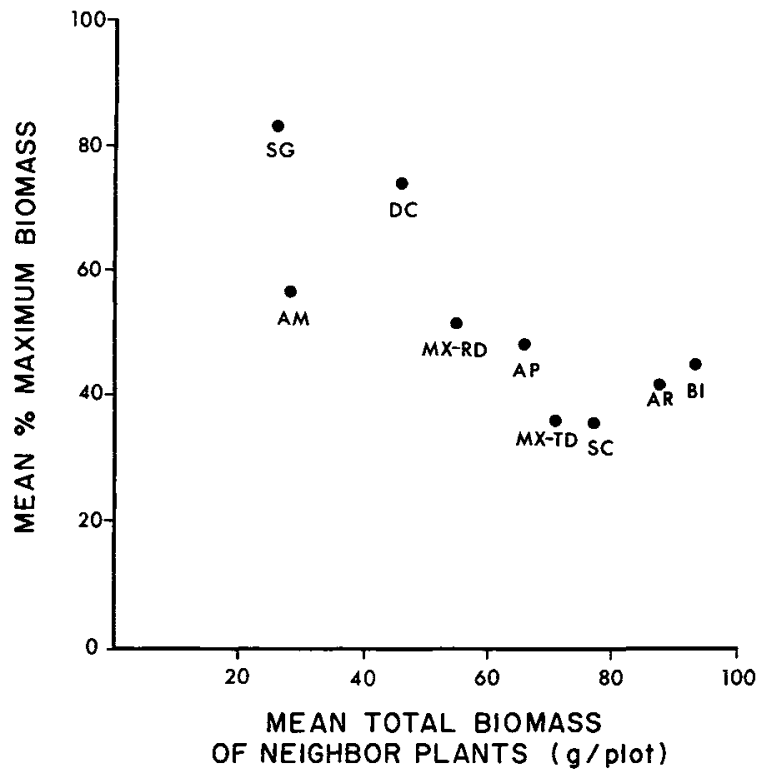

Fig. 1. Mean biomass of Solidago canadensis transplants (target plants) in no-removal plots as a function of mean biomass of the neighbor species in those same plots. Mean target plant biomass with each species as neighbor is expressed as a percentage of target plant biomass in the complete-removal (no competition) plots for that neighbor species. (Species were "removed" by clipping at ground level in April-May and twice more during the growing season.) $\mathrm{SC}=$ Solidago canadensis, $\mathbf{S G}=S$. graminifolia, $\mathrm{AP}=$ Aster pilosus, $\mathrm{DC}=$ Daucus carota, $\mathrm{AM}=$ Achillea millefolium, $\mathrm{AR}=$ Agropyron repens, $\mathrm{BI}=$ Bromus inermis, $\mathrm{MX}-\mathrm{TD}=$ mixture of tall dicots, $\mathrm{MX}-\mathrm{RD}=$ mixture of rosette dicots.

to describe the relationship for each neighbor species (Table 2) and the most appropriate plot area (Table 3). Then, using this function and plot area, the proportion of variance explained by different measures of amount of neighbors was compared for each neighbor species (Table 4).

Shape. - The relationships between total target plant biomass and total neighbor biomass were described better by the nonlinear models than by a linear model, although the differences in $R^{2}$ were usually small (Table 2). Direct fits to the nonlinear functions were used in all cases because transformations (semi-log, log-log, reciprocal, square root) did not succeed in linearizing the data and linear regressions using the transformed data nearly always had lower $R^{2}$ than the direct fits to the nonlinear functions. Probability levels can be assigned only for the linear model; five of the nine neighbor species or mixtures of species had statistically significant linear regressions of target plant biomass on neighbor biomass.

Although the proportion of variance in target plant biomass explained by neighbor biomass was generally similar among the nonlinear models, I used the hyperbolic function (see Table 2) in most subsequent analyses. A hyperbolic function has been found to be the best descriptor of the relationship between mean 


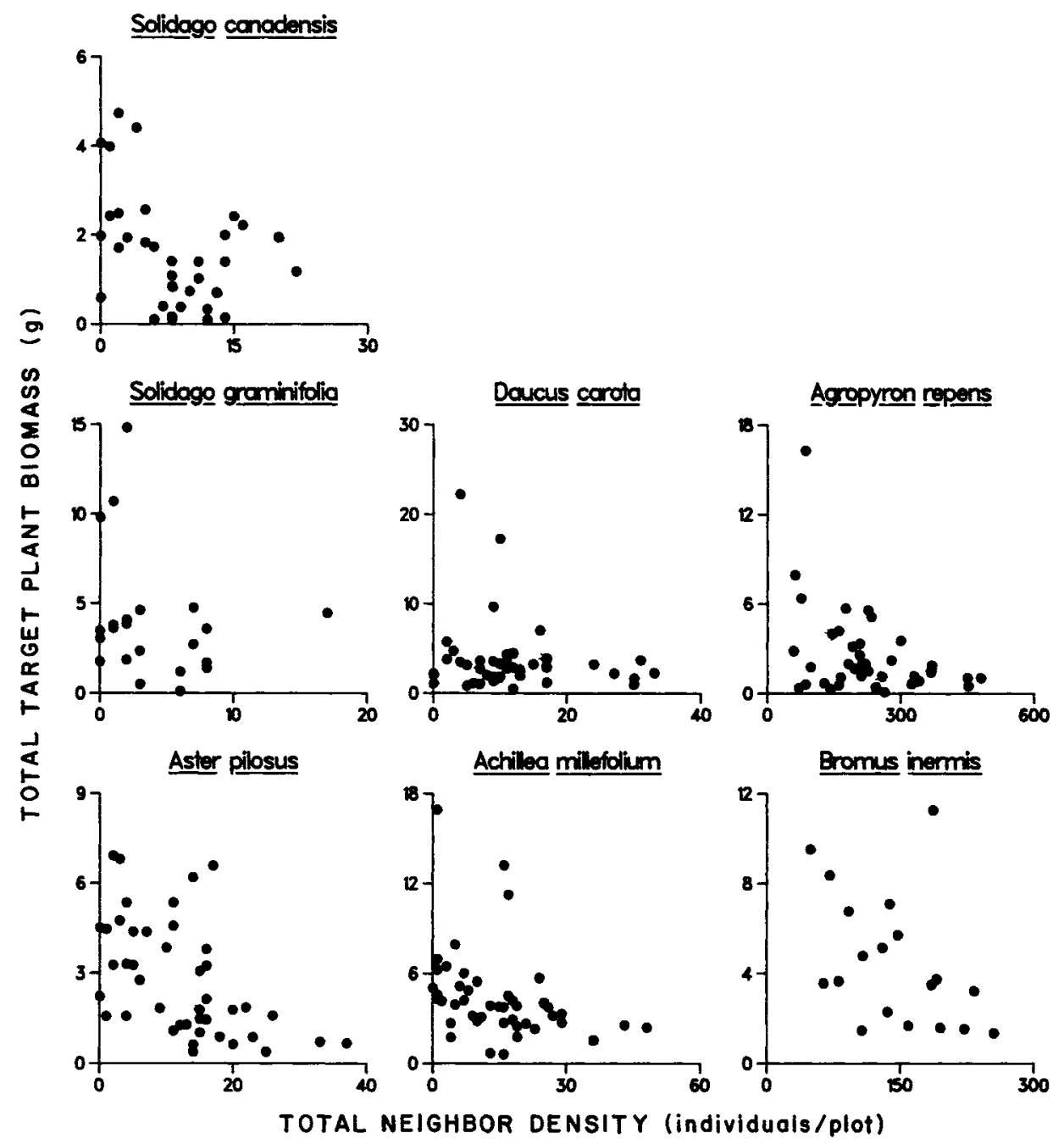

FIG. 2. Effect of neighbor density on individual target Solidago canadensis transplants for each neighbor species. Density data were not available for the mixtures. Note the differences in scale of both axes among graphs. See Table 4 for the $R^{2}$ for these relationships.

plant biomass and total density in many studies of density dependence in single-species stands (Harper 1977, and see Weiner 1982, Silander and Pacala 1985 for use in neighbor experiments).

Neighborhood area. -The $R^{2}$ of the hyperbolic regressions of target plant biomass on neighbor biomass from the first annulus only, from the first two annuli, and from all three annuli were compared to determine the appropriate neighborhood area (Table 3). Except for Agropyron repens, the $R^{2}$ were highest when neighbors in all three annuli were included. In every case except the mixed tall dicots, there was a relatively small change in $R^{2}$ when the third annulus was added to the first two. Thus, for seven of the nine neighbor species or species groups, the $45 \mathrm{~cm}$ diameter plots seemed to be an adequate size to include most of the competitors of the target plants. It is not clear why the $R^{2}$ declined so precipitously with increasing neighborhood size for Agropyron repens.
Effects of distance of neighbors were also evaluated by weighting neighbor biomass in each annulus by the median distance of that annulus from the target plant, on the assumption that near neighbors would have a greater competitive effect than more distant neighbors (Weiner 1982). Both dividing by distance and by distance squared decreased the $R^{2}$ values for almost all species from the values for the simple sum of neighbor biomass in all annuli (Table 3). Similar patterns are seen if only above- or belowground biomass of neighbors is used (D. Goldberg, personal observation). Thus, the simple sum of neighbor biomass in all three annuli was used in all subsequent analyses.

Measures of abundance of neighbors. - Total neighbor biomass, aboveground biomass, belowground biomass, mean height, and density all explained approximately equal proportions of the variance in total target plant biomass (Tables 2 and 4). The highest proportion of the variance in target plant biomass explained by 


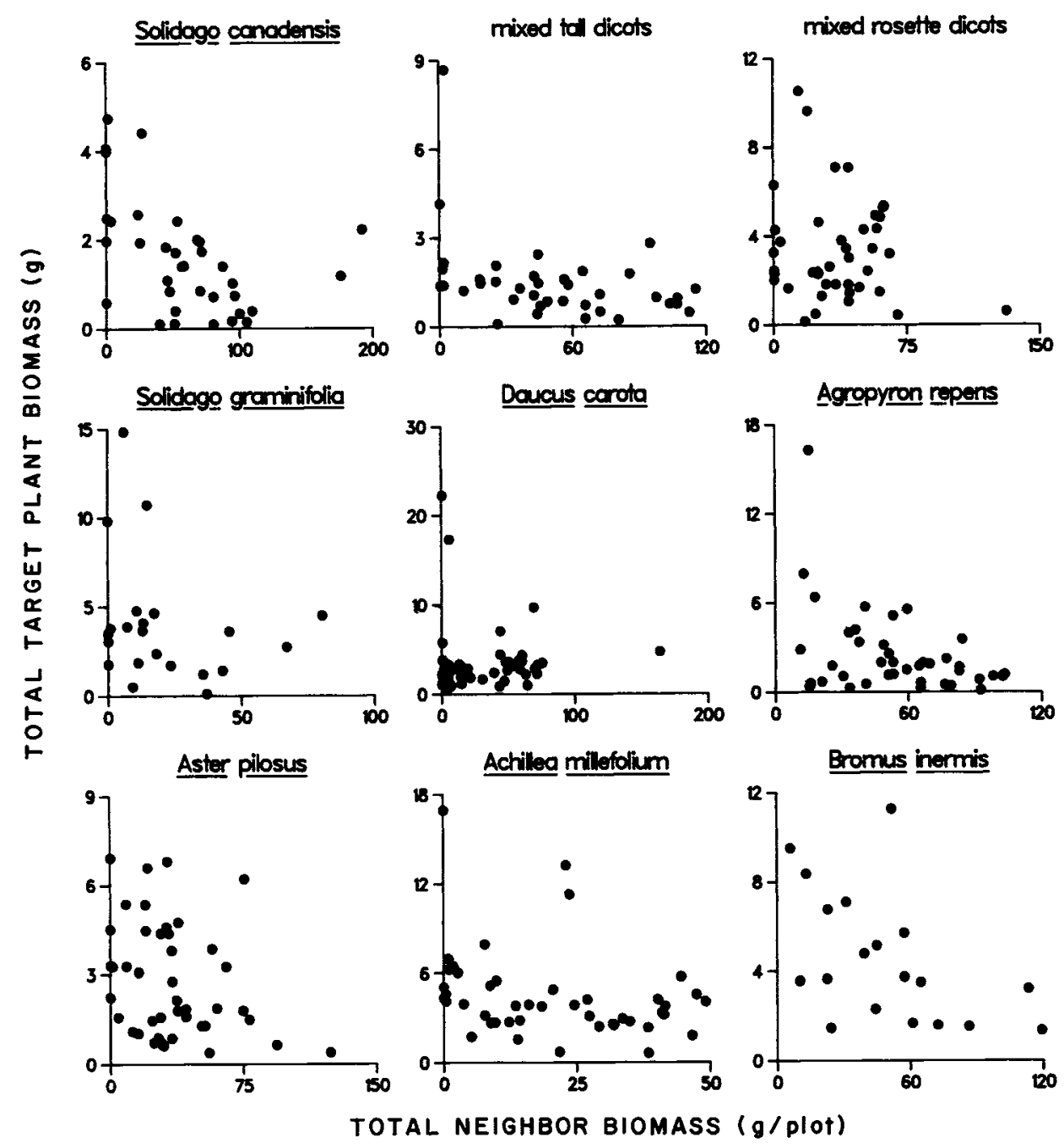

FIG. 3. Effect of neighbor biomass on individual target Solidago canadensis transplants for each neighbor species. Note the differences in scale of both axes among graphs. See Table 2 for the $R^{2}$ for these relationships.

any neighbor component was 0.40 (height of Solidago canadensis neighbors), but was $<0.10$ for half of the neighbor components and species. The proportion of variance in target plant biomass explained by finer biomass components (leaves, stems, roots, rhizomes) was either similar or smaller (D. Goldberg, personal observation). Because there were strong positive correlations among these measures of abundance, the overall similarity in $R^{2}$ values is hardly surprising.

Including plants other than those of the designated neighbor species with live stems within the plots did not increase the proportion of variance in target plant biomass explained. For almost all neighbor species, the $R^{2}$ decreased when unattached roots were included (D. Goldberg, personal observation), suggesting that plants with stems emerging from the ground outside the plots or that had been repeatedly clipped from within the plots had little effect on the target plants. Similarly, including biomass of plants not of the designated neigh- bor species (i.e., clipped plants that had grown back) decreased the $R^{2}$ of regressions of target plant biomass on neighbor biomass (D. Goldberg, personal observation).

\section{Comparison among neighbor species}

Effects on target biomass. - Despite the generally low $R^{2}$ values, comparisons of regression coefficients (competition coefficients) among neighbor species did reveal some patterns. Per-individual neighbor effects on total target plant biomass were strongest for intraspecific competition ( $S$. canadensis), followed by intrageneric competition ( $S$. graminifolia neighbors; Table 5). Perindividual effects were also strongest for neighbor species of the same growth form as the target plant (tall, leafy dicots), intermediate for neighbors with a rosette growth form, and weakest for the grass neighbors. In contrast, there were no consistent patterns in per-gram competitive effects: intraspecific and intra- 
TABLE 2. Shape of target-neighbor relationships for Solidago canadensis transplants. Values are $R^{2}$ from four models for regressions of total target plant biomass $(T)$ on total neighbor biomass $(N)$ at final harvest.

\begin{tabular}{|c|c|c|c|c|c|}
\hline Neighbor species & $n$ & $T=\underset{\text { (linear) }}{T_{\max }-X N \dagger}$ & $\begin{array}{l}T=T_{\max }\left(\mathrm{e}^{X N}\right) \\
\text { (exponential) }\end{array}$ & $T=\underset{\text { (power) }}{T_{\max }(N+1)^{x}}$ & $\begin{array}{c}T=T_{\max } /(1+X N) \\
\text { (hyperbolic) }\end{array}$ \\
\hline \multicolumn{6}{|l|}{ Tall dicots } \\
\hline Solidago canadensis & 35 & $0.21^{* *}$ & 0.35 & 0.30 & 0.36 \\
\hline S. graminifolia & 22 & 0.06 & 0.07 & 0.04 & 0.08 \\
\hline Aster pilosus & 43 & $0.09 *$ & 0.09 & 0.08 & 0.09 \\
\hline Mixed tall dicots & 38 & $0.15^{*}$ & 0.20 & 0.25 & 0.25 \\
\hline \multicolumn{6}{|l|}{ Rosette dicots } \\
\hline Daucus carota & 44 & 0.00 & 0.00 & 0.02 & 0.00 \\
\hline Achillea millefolium & 45 & 0.08 & 0.09 & 0.14 & 0.10 \\
\hline Mixed rosette dicots & 41 & 0.02 & 0.02 & nct & 0.02 \\
\hline \multicolumn{6}{|l|}{ Grasses } \\
\hline Agropyron repens & 40 & $0.16^{*}$ & 0.18 & 0.19 & 0.19 \\
\hline Bromus inermis & 19 & $0.24^{*}$ & 0.24 & 0.24 & 0.24 \\
\hline
\end{tabular}

${ }^{*} P<.05 ;{ }^{* *} P<.01$

$\dagger X=$ regression coefficient.

$¥$ The data did not converge to a minimum residual SS.

growth-form competition were no stronger or weaker in general than interspecific or intergrowth-form competition. These results suggest that the differences in per-individual effects of neighbor species are related to plant size. Per-individual competitive effects were greater for larger-sized neighbor species $\left(r_{s}=0.94 ; \mathrm{df}=\right.$ 5; $P<.01$; Fig. 4).

Because there is no straightforward method for statistical comparisons of regression coefficients from the fits to nonlinear functions, I used the slopes from the linear regressions of target plant biomass on neighbor

TABle 3. Effect of distance to neighbors on target Solidago canadensis transplants.* Values are $R^{2}$ from hyperbolic regressions (see Table 2) of total target plant biomass on total neighbor biomass at final harvest.

\begin{tabular}{|c|c|c|c|c|c|}
\hline Neighbor species & $\begin{array}{c}0-7.5 \\
\mathrm{~cm} \\
\text { radius }\end{array}$ & $\begin{array}{c}0-15 \\
\mathrm{~cm} \\
\text { radius }\end{array}$ & $\begin{array}{c}0-22.5 \\
\mathrm{~cm} \\
\text { radius }\end{array}$ & $\begin{array}{c}\text { Bio- } \\
\text { mass } \\
\bar{\vdots} \\
\text { dis- } \\
\text { tance }\end{array}$ & $\begin{array}{c}\text { Bio- } \\
\text { mass } \\
\dot{\overline{\text { }}} \\
\left(\text { dis- }^{2}\right. \\
\left.\text { tance }^{2}\right)\end{array}$ \\
\hline \multicolumn{6}{|l|}{ Tall dicots } \\
\hline Solidago canadensis & 0.00 & 0.35 & 0.36 & 0.34 & 0.27 \\
\hline S. graminifolia & 0.09 & 0.07 & 0.08 & 0.10 & 0.12 \\
\hline Aster pilosus & 0.11 & 0.06 & 0.09 & 0.10 & 0.11 \\
\hline Mixed tall dicots & 0.01 & 0.09 & 0.25 & 0.21 & 0.16 \\
\hline \multicolumn{6}{|l|}{ Rosette dicots } \\
\hline Daucus carota & 0.00 & 0.00 & 0.00 & 0.00 & 0.00 \\
\hline Achillea millefolium & 0.01 & 0.07 & 0.10 & 0.09 & 0.06 \\
\hline Mixed rosette dicots & 0.02 & 0.01 & 0.02 & 0.01 & 0.00 \\
\hline \multicolumn{6}{|l|}{ Grasses } \\
\hline Agropyron repens & 0.65 & 0.29 & 0.19 & nct & nc \\
\hline Bromus inermis & 0.01 & 0.19 & 0.24 & 0.21 & 0.17 \\
\hline
\end{tabular}

density and biomass to compare competitive effects among neighbor species. As with the nonlinear regressions, the slopes of the linear regressions on neighbor density were more negative for the neighbor species with larger mean sizes of individuals. Using density as the independent variable, the slopes were significantly different among neighbor species $(F=2.183$; $\mathrm{df}=$ 6,$234 ; P<.05$ ). However, the slopes using neighbor biomass as the independent variable were not significantly different $(F=1.117 ; \mathrm{df}=8,309 ; P>.35)$.

Effects on biomass allocation of targets. - There was no consistent relationship between percent allocation by target plants to belowground biomass (roots + rhizomes) and neighbor biomass (Table 6): of two significant linear regressions, one was positive and one was

TABLE 4. Effects of different measures of neighbor abundance on Solidago canadensis transplants. Values are $R^{2}$ from hyperbolic regressions (see Table 2) of total target plant biomass on four measures of abundance of neighbors.

\begin{tabular}{|c|c|c|c|c|c|}
\hline Neighbor species & $n$ & $\begin{array}{c}\text { Above } \\
\text { ground } \\
\text { bio- } \\
\text { mass }\end{array}$ & $\begin{array}{l}\text { Below- } \\
\text { ground } \\
\text { bio- } \\
\text { mass }\end{array}$ & Height & $\begin{array}{c}\text { Den- } \\
\text { sity }\end{array}$ \\
\hline \multicolumn{6}{|l|}{ Tall dicots } \\
\hline Solidago canadensis & 35 & 0.36 & 0.35 & 0.40 & 0.24 \\
\hline S. graminifolia & 22 & 0.0 & 0.07 & 0.04 & 0.09 \\
\hline Aster pilosus & 43 & 0.07 & 0.15 & 0.03 & 0.25 \\
\hline Mixed tall dicots & 38 & 0.25 & 0.21 & $\ldots *$ & $\cdots$ \\
\hline \multicolumn{6}{|l|}{ Rosette dicots } \\
\hline Daucus carota & 44 & 0.02 & 0.00 & 0.08 & 0.02 \\
\hline Achillea millefolium & 45 & 0.09 & 0.11 & 0.07 & 0.13 \\
\hline Mixed rosette dicots & 41 & 0.01 & 0.02 & $\cdots$ & $\cdots$ \\
\hline \multicolumn{6}{|l|}{ Grasses } \\
\hline Agropyron & 40 & 0.12 & nct & 0.07 & nc \\
\hline Bromus inermis & 19 & 0.21 & 0.25 & 0.18 & 0.18 \\
\hline
\end{tabular}

* No data on height or density were available for the mixtures.

$\uparrow$ The data did not converge to a minimum residual SS 
TABle 5. Per-individual and per-gram competitive effects of neighbors on $S$. canadensis transplants. Values are the intercepts $\left(T_{\max }\right)$ and regression coefficients $(X)$ from the fit to hyperbolic functions $\left[T=T_{\max } /(1+X N)\right]$ where $T=$ total target plant biomass and $N=$ total neighbor biomass or neighbor density.

\begin{tabular}{|c|c|c|c|c|c|}
\hline \multirow[b]{2}{*}{ Neighbor species } & \multirow[b]{2}{*}{$n$} & \multicolumn{4}{|c|}{ Regression intercepts and coefficients } \\
\hline & & $T_{\max } *(\mathrm{SD}) \ddagger$ & $X \dagger(\mathrm{SD})$ & $T_{\max }(\mathrm{SD})$ & $X(\mathrm{sD})$ \\
\hline & & \multicolumn{2}{|c|}{ Total neighbor biomass } & \multicolumn{2}{|c|}{ Total neighbor density } \\
\hline Tall dicots & & & & & \\
\hline $\begin{array}{l}\text { Solidago canadensis } \\
\text { S. graminifolia } \\
\text { Aster pilosus } \\
\text { Mixed tall dicots }\end{array}$ & $\begin{array}{l}35 \\
22 \\
43 \\
38\end{array}$ & $\begin{array}{l}3.00(0.39) \\
5.38(1.35) \\
3.78(0.65) \\
3.15(0.55)\end{array}$ & $\begin{array}{l}0.022(0.008) \\
0.021(0.024) \\
0.012(0.012) \\
0.035(0.016)\end{array}$ & $\begin{array}{c}2.89(0.51) \\
5.46(1.41) \\
4.52(0.69) \\
\cdots \S\end{array}$ & $\begin{array}{l}0.138(0.066) \\
0.124(0.133) \\
0.061(0.028)\end{array}$ \\
\hline \multicolumn{6}{|l|}{ Rosette dicots } \\
\hline $\begin{array}{l}\text { Daucus carota } \\
\text { Achillea millefolium } \\
\text { Mixed rosette dicots }\end{array}$ & $\begin{array}{l}44 \\
45 \\
41\end{array}$ & $\begin{array}{l}3.94(0.93) \\
6.02(0.88) \\
3.74(0.72)\end{array}$ & $\begin{array}{l}0.002(0.007) \\
0.022(0.013) \\
0.004(0.006)\end{array}$ & $\begin{array}{c}4.54(1.40) \\
6.45(1.02) \\
\cdots\end{array}$ & $\begin{array}{c}0.022(0.036) \\
0.038(0.021) \\
\ldots\end{array}$ \\
\hline \multicolumn{6}{|l|}{ Grasses } \\
\hline $\begin{array}{l}\text { Agropyron repens } \\
\text { Bromus inermis }\end{array}$ & $\begin{array}{l}40 \\
19\end{array}$ & $\begin{array}{r}10.83(8.08) \\
8.15(2.38)\end{array}$ & $\begin{array}{l}0.079(0.089) \\
0.019(0.015)\end{array}$ & $\begin{array}{c}\mathrm{nc} \| \\
11.91(8.05)\end{array}$ & $\begin{array}{c}\mathrm{nc} \\
0.013(0.015)\end{array}$ \\
\hline
\end{tabular}

* The intercept $\left(T_{\max }\right)$ is the estimated target plant biomass with no neighbors present.

‡ The asymptotic standard deviations of the parameter estimates for the regression coefficients (Dixon 1983). $R^{2}$ values for the regressions are in Tables 2 and 4.

$\dagger$ The regression coefficient $(X)$ is the per-gram (regressions on neighbor biomass) or per-individual (regressions on neighbor density) competitive effect of each neighbor species. Larger values indicate stronger effects.

$\S$ No density data were available for the mixtures.

$\|$ The data did not converge to a minimum residual SS.

negative. However, the aboveground growth form of the target plants was related to neighbor biomass and in the same direction for all neighbor species (Table 6): eight of nine linear regressions of the ratio of height to shoot biomass of target plants on total neighbor biomass were positive (four significant at $P<.05$ ). Target plants of the same aboveground biomass were taller in denser vegetation, suggesting that there was competition for light.

\section{Response of different clones to neighbors}

In addition to comparisons of effects among neighbor species, the experimental design allowed comparison of the responses of different clones of the target plants to neighbors. Because there were only two transplants per clone for each neighbor species, analysis of among-clone response to particular neighbor species was not possible. Within each clone, there was a negative relationship between target plant biomass and neighbor biomass (linear $r$ values ranged from -0.26 to -0.40$)$. The slopes for these regressions were not significantly different among clones $(F=0.659$; df $=$ 23,$277 ; P>.50$ ). There were also no significant differences in mean target plant biomass among clones either when neighbor biomass was ignored $(F=0.768$; df $=23,300 ; P>.50$ ) or when target plant biomass was adjusted for neighbor biomass in an analysis of covariance $(F=0.896 ; \mathrm{df}=23,300 ; P>.50)$.

TABLE 6. Effects of neighbor biomass on biomass allocation of Solidago canadensis transplants. Values are coefficients from linear regressions of target plant components on total neighbor biomass. See Table 5 for sample sizes.

\begin{tabular}{|c|c|c|c|c|c|c|}
\hline \multirow[b]{2}{*}{ Neighbor species } & \multicolumn{3}{|c|}{ Percent allocation to belowground biomass } & \multicolumn{3}{|c|}{ Height per unit shoot biomass $(\mathrm{cm} / \mathrm{g})$} \\
\hline & $r$ & Slope & Intercept & $r$ & Slope & Intercept \\
\hline \multicolumn{7}{|l|}{ Tall dicots } \\
\hline $\begin{array}{l}\text { Solidago canadensis } \\
\text { S. graminifolia } \\
\text { Aster pilosus } \\
\text { Mixed tall dicots }\end{array}$ & $\begin{array}{l}-0.12 \\
0.01 \\
0.48^{* *} \\
-0.03\end{array}$ & $\begin{array}{r}-0.000 \\
0.000 \\
0.002 \\
-0.000\end{array}$ & $\begin{array}{l}0.229 \\
0.214 \\
0.132 \\
0.226\end{array}$ & $\begin{array}{l}0.28 \\
0.10 \\
0.46^{* *} \\
0.37^{*}\end{array}$ & $\begin{array}{l}0.18 \\
0.03 \\
0.14 \\
0.19\end{array}$ & $\begin{array}{l}32.03 \\
18.01 \\
15.63 \\
24.03\end{array}$ \\
\hline \multicolumn{7}{|l|}{ Rosette dicots } \\
\hline $\begin{array}{l}\text { Daucus carota } \\
\text { Achillea millefolium } \\
\text { Mixed rosette dicots }\end{array}$ & $\begin{array}{r}0.28 \\
0.05 \\
-0.14\end{array}$ & $\begin{array}{r}0.001 \\
0.000 \\
-0.001\end{array}$ & $\begin{array}{l}0.193 \\
0.210 \\
0.258\end{array}$ & $\begin{array}{r}-0.16 \\
0.26 \\
0.07\end{array}$ & $\begin{array}{r}-0.05 \\
0.08 \\
0.02\end{array}$ & $\begin{array}{l}22.45 \\
13.34 \\
18.59\end{array}$ \\
\hline \multicolumn{7}{|l|}{ Grasses } \\
\hline $\begin{array}{l}\text { Agropyron repens } \\
\text { Bromus inermis }\end{array}$ & $\begin{array}{l}-0.04 \\
-0.60^{* *}\end{array}$ & $\begin{array}{l}-0.000 \\
-0.001\end{array}$ & $\begin{array}{l}0.182 \\
0.347\end{array}$ & $\begin{array}{l}0.43^{* *} \\
0.63^{* *}\end{array}$ & $\begin{array}{l}0.32 \\
0.11\end{array}$ & $\begin{array}{l}11.36 \\
10.41\end{array}$ \\
\hline
\end{tabular}

${ }^{*} P<.05 ;{ }^{* *} P<.01$ 
TABLE 7. Indexes of environmental conditions for plots with different neighbor species. Values with the same letter within a column are not significantly different by a Bonferroni $t$ test.

\begin{tabular}{|c|c|c|c|c|c|c|c|}
\hline \multirow[b]{4}{*}{ Neighbor species } & & \multicolumn{4}{|c|}{ Complete-removal plots } \\
\hline & \multirow{2}{*}{\multicolumn{3}{|c|}{$\frac{\text { All plots }}{\text { Soil proportion }(\text { silt }+ \text { clay })}$}} & \multirow{2}{*}{\multicolumn{3}{|c|}{ Final target biomass (g) }} & \multirow{3}{*}{$\begin{array}{l}\text { Correlation }(r) \text { of } \\
\text { soil texture with } \\
\text { final biomass } \\
\text { of target plant }\end{array}$} \\
\hline & & & & & & & \\
\hline & $n$ & $\overline{\bar{X}}$ & SD & $n$ & $\overline{\bar{X}}$ & SD & \\
\hline \multicolumn{8}{|l|}{ Tall dicots } \\
\hline Solidago canadensis & 34 & $0.35^{\mathrm{a}}$ & 0.07 & 7 & 2.89 & 1.44 & 0.58 \\
\hline S. graminifolia & 22 & $0.35^{\mathrm{a}}$ & 0.05 & 5 & 4.38 & 3.13 & 0.27 \\
\hline Aster pilosus & 43 & $0.34^{\mathrm{ab}}$ & 0.07 & 8 & 3.81 & 1.73 & 0.61 \\
\hline Mixed tall dicots & 38 & $0.34^{\mathrm{a}}$ & 0.07 & 7 & 3.00 & 2.70 & 0.39 \\
\hline \multicolumn{8}{|l|}{ Rasette dicots } \\
\hline Daucus carota & 44 & $0.36^{\mathrm{a}}$ & 0.07 & 9 & 5.06 & 6.59 & -0.56 \\
\hline Achillea millefolium & 45 & $0.30^{\text {bd }}$ & 0.05 & 9 & 6.52 & 4.05 & 0.35 \\
\hline Mixed rosette & 41 & $0.31^{\text {abd }}$ & 0.07 & 7 & 3.48 & 1.49 & -0.57 \\
\hline \multicolumn{8}{|l|}{ Grasses } \\
\hline Agropyron repens & 39 & $0.12^{\mathrm{c}}$ & 0.04 & 6 & 3.20 & 3.23 & 0.11 \\
\hline Bromus inermis & 19 & $0.28^{\mathrm{d}}$ & 0.05 & 5 & 5.93 & 3.35 & 0.09 \\
\hline $\begin{array}{l}F_{\text {ne }} \\
\text { df }\end{array}$ & & $\begin{array}{l}50.45^{* *} \\
8,316\end{array}$ & & & $\begin{array}{l}0.98 \\
8,54\end{array}$ & & \\
\hline
\end{tabular}

*** $P<.001 ;$ NS $=$ nonsignificant.

\section{Environmental effects on target plants}

One aspect of the experimental design could have confounded some of the comparisons of competitive effect among neighbor species. I used experimentally imposed density gradients around the target plants rather than natural density gradients because a natural gradient could indicate variation in some underlying abiotic factor, which in turn could directly affect target plant growth. By starting with high density of plants in all the plots for a particular neighbor species, I hoped to minimize any variation in abiotic conditions over the density gradient of a single neighbor species. However, if different species were at high density or biomass under different environmental conditions, this method could have increased differences in target plant performance among neighbor species.

Soil texture was used as an overall index of environmental conditions because both soil moisture and nutrient availability have been found to be higher in finer-textured soils in these old fields (P. A. Werner, personal communication). Although the neighbor species did occur in different soil environments (Table 7), there were no significant differences among neighbor species in final target plant biomass in plots with all neighbors removed (no competition; Table 7). Final target plant biomass in these plots was not significantly correlated with clay and silt content of soil either within neighbor species (Table 7) or using all complete-removal plots in a single correlation analysis $(r=0.03$; $\mathrm{df}=61 ; P>.50$ ). Thus, although sample sizes for this analysis were limited, the environmental differences that exist among plots for different neighbor species do not seem to affect the growth of the target plants when there is no competition.

\section{DisCusSION}

The results clearly indicate that the $S$. canadensis transplants were, on the average, inhibited by the presence of neighbors. At the final harvest, transplants in the presence of neighbors at their natural densities were 38 to $83 \%$ of the average size of transplants growing without any neighbors (Fig. 1). In addition, the relationships between individual transplant growth and neighbor density or neighbor biomass were all negative (Figs. 2 and 3).

Numerous other field experiments in herbaceous plant communities have also demonstrated significant reductions in plant growth or survival in the presence of neighbors (e.g., Putwain and Harper 1970, Pinder 1975, Allen and Forman 1976, Gross 1980, Fowler 1981, Silander and Antonovics 1982). In many of these experiments, there were also significant differences in the effects of removing different species or groups of species of competitors. However, these experiments generally do not distinguish whether species have different competitive effects because of differences in total abundance (i.e., removing a rare species has less effect than removing a common species) or because of differences among species in per-individual or per-unitsize effects.

In the experiments described in this paper, I also found significant differences among species in competitive effect simply comparing mean target plant biomass in the presence vs. absence of neighbors. In addition, there were significant differences among neigh bor species in per-individual competitive effects. In particular, intraspecific competition was stronger than interspecific competition and intragrowth-form competition was stronger than intergrowth-form competition. 
However, the magnitude of these effects at both the population level and individual level was strongly related to total abundance (population; Fig. 1) and mean plant size (individual; Fig. 4) of each neighbor species. The stronger intraspecific per-individual effect found in this experiment may be a coincidence because the target species was the species with the largest mean individual size of all the neighbor species used. If the target species had been, for example, Bromus inermis, the per-individual effect of $S$. canadensis neighbors would likely still have been larger than for any of the other species because it has the largest mean plant size.

In contrast to these results for per-individual effects, I could not detect any significant differences in pergram competitive effects among the neighbor species, and there were no patterns in the magnitude of pergram effects relative to relatedness or growth form of the neighbor species. The lack of statistically significant differences among species in per-gram competitive effects may be due in part to the high variance in biomass of target individuals that was apparently unrelated to competitive environment. A maximum of $36 \%$ and usually much less of the variance in target plant biomass was attributable to variation in neighbor biomass (see below for discussion of possible sources of the residual variance). Thus, there was relatively little statistical power to detect differences among neighbor species. Further, the statistical comparison of regression coefficients was done using slopes from the linear regressions, although the actual relationship between target biomass and neighbor density or neighbor biomass appears to be nonlinear (Figs. 2 and 3). Combined with the much higher variance in target biomass at low than at high neighbor density or biomass, this means that the residuals of the linear regressions are nonrandomly distributed. Given these departures from the assumptions of regression analysis, we cannot attach too much importance to the precise values of the regression coefficients and associated probability levels.

Despite these limitations of the data and its analysis, there are several reasons why it is reasonable to conclude that the neighbor species differ much less in perunit-size effects than in per-individual effects, even if we cannot conclude that subtle differences in per-unitsize effects do not exist. The low statistical power and violations of the assumptions of regression analysis apply to the relationships of target biomass with both neighbor density and neighbor biomass, yet statistical differences in per-individual competitive effects could be detected among neighbor species. Further, the strong relationship between the coefficients from the regressions on density and mean neighbor size (Fig. 4) and the obvious biological interpretation of this relationship suggest that at least the rankings of per-individual competitive effects reflect a real phenomenon. By extension, we can argue that the lack of pattern in the rankings of per-unit size competitive effects also reflect a real phenomenon.

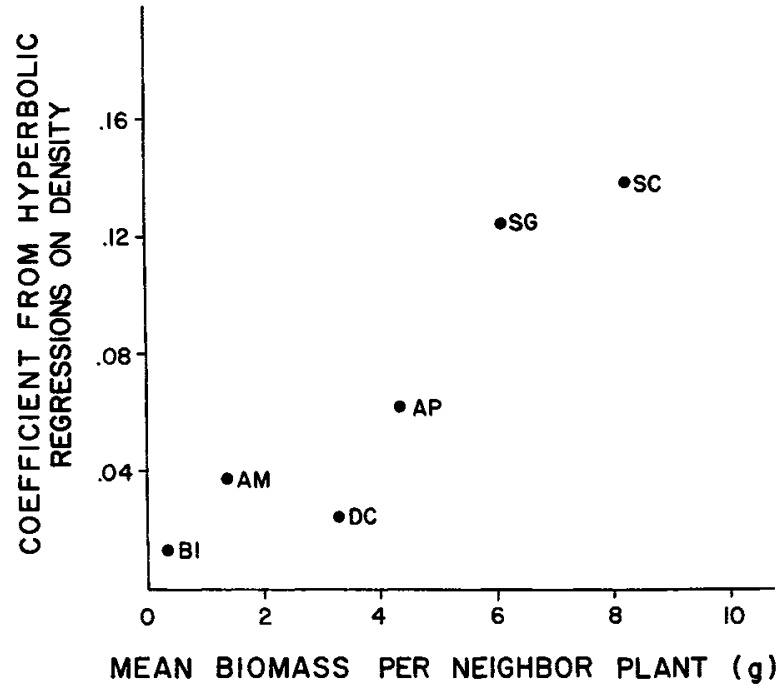

FIG. 4. Dependence of per-individual competitive effect of each neighbor species on mean plant size of each neighbor species. The per-individual effects are the regression coeffcients from the hyperbolic regressions of total target plant biomass on neighbor density. See Fig. 1 legend for species abbreviations.

The strong relationship between per-individual competitive effect and mean plant size is hardly surprising because total uptake of resources obviously increases with size. The more important result is the lack of pattern in per-unit-size competitive effects relative to taxonomic relatedness or growth form. There are at least two classes of reasons to expect differences in the magnitude of competition among species or among growth forms. First, if plants partition resources such that each species has at least a partial refuge from competition, intraspecific per-unit-size effects should be stronger than interspecific per-unit-size effects. Although opportunities for resource partitioning are relatively limited in plants because they all require the same resources, plants may differ in ratio of resources required (Tilman 1982), in root depth (e.g., Berendse 1981), and/or in timing of resource uptake (e.g., Fowler and Antonovics 1981). Second, even in the absence of significant resource partitioning, the same measure of plant size could translate into different rates of depletion of resources for different species. For example, if there is strong competition for light, per-gram or perunit leaf surface area effects of grasses might be expected to be less than for tall leafy dicots if the vertical orientation of grass leaves results in less shading perunit-size.

The results of this experiment suggest that neither resource partitioning nor differential rates of resource depletion results in differences in per-unit-size competitive effect in this group of co-occurring species, despite the range of growth forms used. It is difficult to assess the generality of these results because there 
are very few other field or even greenhouse experiments that have explicitly compared per-unit-size competitive effects among co-occurring species. In greenhouse experiments, we have found equivalence of per-unitsize competitive effects among several sets of species of similar growth form (Goldberg and Fleetwood 1987, K. L. Landa and D. E. Goldberg, personal communication). Two field experiments in herbaceous plant communities have also found very similar competitive effects among neighbor species on a per-gram basis (Peart and Foin 1985, Miller and Werner 1987). Both of these studies used mean response of several "target" individuals to gradients in biomass of neighbors rather than the response of single target individuals in their analyses. Thus, there was much less variability and so greater statistical power to detect differences. In contrast, Caldwell et al. (1985) demonstrated strong differences in ability to compete for phosphorus between "similar-sized" plants of two related grass species.

\section{Implications for community structure}

The lack of evidence for resource partitioning found in this study is consistent with the hypothesis that coexisting plant species are those that are equivalent in competitive ability for shared resources (Aarssen 1983, Agren and Fagerstrom 1984, Hubbell and Foster 1986), rather than those that partition resources in some way and so compete less strongly. However, the comparison of per-unit-size competitive effects reported in this paper is not a complete test of this hypothesis for at least two reasons. First, species with equivalent per-unitsize competitive effects may differ in average per-individual effects because of differences in growth rate, morphological constraints on maximum potential size, and/or differences in longevity that result in different size distributions of individuals among species (Buss 1981). Thus, species may differ in the population dynamic consequences of competition even if they are completely equivalent in per-unit-size competitive effects measured at any one time.

Second, competitive effect is only one component of competitive ability, the ability to deplete resources and make them unavailable to other plants. Competitive ability also includes the response of individuals to the presence of competitors, the ability to grow, survive, and reproduce despite depletion of resource levels by neighbors (Goldberg and Werner 1983). Coexistence by equivalence of competitive ability requires equivalence of competitive response as well as of competitive effect. Significant differences in competitive response have been shown in several experiments demonstrating statistical equivalence of per-unit-size competitive effects among the same species (Goldberg and Fleetwood 1987, Miller and Werner 1987, K. L. Landa and D. E. Goldberg, personal communication).

If plants are more likely to differ in competitive response than in competitive effect, it suggests that we shift our emphasis from the effects of competition be- tween particular pairs of species to the ecological and evolutionary response of each species to diffuse competition from the entire community. There may be strong selection on ability to compete with any plants, regardless of species, even if coevolution between particular pairs of species is unlikely (cf. Connell 1980). Similarly, the invasibility of a community may be a function of the mean and spatial patchiness of standing crop and productivity of that community rather than the species composition of the community or of any particular patch (cf. Grime 1977, del Moral 1983, Wilson and Keddy 1986). Indeed, the latter idea is implicit in most empirical studies of the effect of competition on the distribution of plant species. To determine if the absence of a species from a community is a result of competition, most researchers have simply compared ability to grow and survive in the absence of any competition with performance with the entire community present (e.g., Werner 1978, Goldberg 1985a, Gurevitch 1986, Wilson and Keddy 1986).

\section{Variability among target individuals}

The discussion so far has mentioned the striking variability among target individuals only as it concerns the ecologist's ability to detect differences in competitive effect among species. However, the variability itself may have important implications for our ideas about the effect of competition on community structure. Whether or not there are differences in competitive effect or response among species, there may be little impact of competition of any type on the distribution and abundance of the species if a large component of the fate of any individual is determined by factors other than competition (Strong 1986). However, the form of the variation among target individuals in relation to competitive environment found in this experiment suggests that competition does play an important role. Variance among target individuals was considerably higher at low neighbor density and biomass than at high neighbor density and biomass (Figs. 2 and 3 ). Because the plots with low density and biomass of neighbors were a result of experimental removal of plants, most plants in the natural population probably experience relatively high competition intensity.

The form of the variation among target individuals relative to neighbor density or biomass also suggests that competition acts as a boundary constraint on maximum potential size of individuals rather than as an accurate predictor of actual size. Part of the cause of this boundary effect may be experimental error. In particular, the process of transplanting could have resulted in damage to some target plants so that they were incapable of growing to a large size even with relatively few competitors. However, several other studies have found similar boundary effects in field neighborhood analyses using naturally growing target individuals rather than experimental transplants (Waller 1981, 
Liddle et al. 1982, R. Holmes, personal communication).

A general alternative explanation for the boundary effect is that it is the inevitable result of portraying a multidimensional process in only two dimensions. That is, factors other than competition also influence target individual performance. This does not necessarily mean that plants with growth rates below the competition boundary are unaffected by competition. Plants with different genotypes, initial sizes, herbivore or pathogen loads, or growing in abiotically different microsites could each have unique, but highly predictable responses to competition. Ignoring such factors would make it appear as if there were little effect of competitors. For example, in an experiment designed explicitly to compare the responses of $S$. canadensis transplants of different genotypes to neighborhood competition, I found significant differences in the slopes of regressions of target plant biomass on neighbor biomass among clones of the target plants (Goldberg 1985b). In the same experiment, I also found significant effects of initial rhizome weight of the transplants and of herbivores on individual performance. All of these factors, as well as spatial heterogeneity in the abiotic environment may underlie some of the variability among target individuals growing at similar neighbor density or biomass found in this study.

Partitioning of the sources of variance in individual fitness is one way to start documenting patterns in the relative importance of factors affecting species distribution and abundances. In three other published studies of neighborhood competition in natural plant communities (all involving only intraspecific competition), the proportion of the variance in individual performance explained by some measure of competitive environment ranged from 0 to $86 \%$ (Waller 1981 , Weiner $1982,1984)$. Thus, 14 to $100 \%$ of the variance was explained by factors other than competition or that interact with competition in some way (Waller 1981, Weiner 1982, 1984). Clearly, more comparisons among communities and among species are needed to provide a basis for documenting and understanding patterns in the importance of competition relative to other factors affecting plant fitness and species abundance.

\section{ACKNOWLEDGMENTS}

This research was supported by the National Science Foundation DEB81-11315. I thank P. Carlton, V. Dunevitz, J. Seeley, and K. Wiest for excellent field and laboratory assistance and A. A. Winn, S. Gleeson, T. Miller, C. W. Osenberg, and $E$. E. Werner for their valuable comments on various drafts of the manuscript. This is Kellogg Biological Station Contribution Number 593.

\section{Literature Cited}

Aarssen, L. W. 1983. Ecological combining ability and competitive combining ability in plants: towards a general evolutionary theory of coexistence in systems of competition. American Naturalist 122:707-731.

Agren, G.I., and T. Fagerstrom. 1984. Limiting dissimilarity in plants: randomness prevents exclusion of species with similar competitive abilities. Oikos 43:369-375.

Allen, E. B., and R. T. T. Forman. 1976. Plant species removals and old-field community structure and stability. Ecology 57:1233-1243.

Berendse, F. 1981. Competition and equilibrium in grassland communities. Dissertation. University of Utrecht, Utrecht, The Netherlands. Grassland Research Group Publication Number 44.

Buss, L. W. 1981. Competitive intransitivity and size-frequency distributions of interacting populations. Proceedings of the National Academy of Sciences (USA) 77:53555359.

Caldwell, M. M., D. M. Eissenstat, J. H. Richards, and M. F. Allen. 1985. Competition for phosphorus: differential uptake from dual-labelled soil interspaces between shrub and grass. Science 229:384-386.

Connell, J. H. 1980 . Diversity and the coevolution of competitors, or the ghost of competition past. Oikos 35:131138.

138. 1983. On the prevalence and relative importance of interspecific competition: evidence from field experiments. American Naturalist 122:661-696.

Day, P. R. 1965. Particle fractionation and particle size analysis. Pages $546-566$ in C. A. Black, editor. Methods of soil analysis. American Society of Agronomy, Madison, Wisconsin, USA.

del Moral, R. 1983. Competition as a control mechanism in subalpine meadows. American Journal of Botany 70: 232-245.

Dixon, W. J. 1983. BMDP statistical software. University of California Press, Berkeley, California, USA.

Fowler, N. L. 1981. Competition and coexistence in a North Carolina grassland. II. The effects of the experimental removal of species. Journal of Ecology 69:843-854.

- 1984. The role of germination date, spatial arrangement, and neighbourhood effects in competitive interactions in Linum. Journal of Ecology 72:307-318.

Fowler, N., and J. Antonovics. 1981. Competition and coexistence in a North Carolina grassland. I. Patterns in undisturbed vegetation. Journal of Ecology 69:825-842.

Goldberg, D. E. 1985a. Effects of soil pH, competition, and seed predation on the distribution of two tree species. Ecology 66:503-511.

․ $1985 b$. Components of variation of individual plant success. Studies in Plant Ecology 16:41-42.

Goldberg, D. E., and L. Fleetwood. 1987. Comparison of competitive effects and responses among annual plants. Journal of Ecology, in press.

Goldberg, D. E., and P. A. Werner. 1983. Equivalence of competitors in plant communities: a null hypothesis and a field experimental approach. American Journal of Botany 70:1098-1104.

Grime, J. P. 1977. Evidence for the existence of three primary strategies in plants and its relevance to ecological and evolutionary theory. American Naturalist 111:1169-1194.

Gross, K. L. 1980. Colonization of Verbascum thapsus (Mullein) in an old field in Michigan: the effects of vegetation. Journal of Ecology 68:919-927.

Gurevitch, J. 1986. Competition and the local distribution of the grass Stipa neomexicana. Ecology 67:46-57.

Harper, J. L. 1977. Population biology of plants. Academic Press, New York, New York, USA.

Hubbell, S. P., and R. B. Foster. 1986. Biology, chance, and history and the structure of tropical rain forest tree communities. Pages 314-340 in J. Diamond and T. J. Case, editors. Community ecology. Harper \& Row, New York, New York, USA.

Liddle, M. J., C. S. J. Budd, and M. J. Hutchings. 1982. Population dynamics and neighbourhood effects in establishing swards of Festuca rubra. Oikos 38:52-59. 
Mack, R. N., and J. L. Harper. 1977. Interference in dune annuals: spatial pattern and neighborhood effects. Journal of Ecology 65:345-364.

Miller, T. E., and P. A. Werner. 1987. Competitive effects and responses between plant species in a first-year old-field community. Ecology 68:1201-1210.

Mithen, R., J. L. Harper, and J. Weiner. 1984. Growth and mortality of individual plants as a function of "available area." Oecologia (Berlin) 62:57-60.

Pacala, S. W., and J. A. Silander. 1985. Neighborhood models of plant population dynamics. I. Single-species models of annuals. American Naturalist 125:385-411.

Peart, D. R., and T. C. Foin. 1985. Analysis and prediction of population and community change: a grassland case study. Pages 313-340 in J. White, editor. The population structure of vegetation. Handbook of Vegetation Science 3. Dr. W. Junk, Dordrecht, The Netherlands.

Pinder, J. E., III. 1975. Effects of species removals on an old-field community. Ecology 56:747-751.

Putwain, P. D., and J. L. Harper. 1970. Studies in the dynamics of plant populations. III. The influence of associated species on populations of Rumex acetosa $\mathrm{L}$. and $R$. acetosella L. in grassland. Journal of Ecology 58:251-264.

Schoener, T. W. 1983. Field experiments on interspecific competition. American Naturalist 122:240-285.

Shmida, A., and S. Ellner. 1984. Coexistence of plant species with similar niches. Vegetatio 58:29-55.

Silander, J. A., and J. Antonovics. 1982. Analysis of interspecific interactions in a coastal plant community - a perturbation approach. Nature 298:557-560.
Silander, J. A., and S. W. Pacala. 1985. Neighborhood predictors of plant performance. Oecologia (Berlin) 66:256263.

Sokal, R. R., and F. J. Rohlf. 1981. Biometry. Second edition. W. H. Freeman, San Francisco, California, USA.

Strong, D. R. 1986. Density vagueness: abiding the variance in the demography of real populations. Pages 257-268 in J. Diamond and T. J. Case, editors. Community ecology. Harper \& Row, New York, New York, USA.

Tilman, D. 1982. Resource competition and community structure. Monographs in population biology. Princeton University Press, Princeton, New Jersey, USA.

Waller, D. M. 1981. Neighborhood competition in several violet populations. Oecologia (Berlin) 51:116-122.

Weiner, J. 1982. A neighborhood model of annual plant interference. Ecology 63:1237-1241.

- 1984. Neighbourhood interference amongst Pinus rigida individuals. Journal of Ecology 72:183-195.

Werner, P. A. 1978. Patterns and processes of niche differentiation among goldenrods (Solidago spp.). Pages 17-21 in $\mathrm{H}$. I. Oka and O. Kitagawa, editors. The dynamics of speciation in plants and animals. U.S.-Japan Cooperative Science Program.

Werner, P. A., I. K. Bradbury, and R. S. Gross. 1980. The biology of Canadian weeds. 45. Solidago canadensis $\mathrm{L}$. Canadian Journal of Plant Sciences 60:1393-1409.

Wilson, S. D., and P. A. Keddy. 1986. Measuring diffuse competition along an environmental gradient: results from a shoreline plant community. American Naturalist 127: 862-869. 